\title{
Tree-, stand- and site-specific controls on landscape-scale patterns of transpiration
}

\author{
Sibylle Kathrin Hassler ${ }^{1,2}$, Markus Weiler ${ }^{3}$, and Theresa Blume ${ }^{2}$ \\ ${ }^{1}$ Karlsruhe Institute of Technology (KIT), Institute of Water and River Basin Management, Chair of Hydrology, \\ Karlsruhe, Germany \\ ${ }^{2}$ Helmholtz Centre Potsdam, GFZ German Research Centre for Geosciences, Section Hydrology, Potsdam, Germany \\ ${ }^{3}$ Hydrology, Faculty of Environment and Natural Resources, University of Freiburg, Freiburg, Germany
}

Correspondence: Sibylle Kathrin Hassler (sibylle.hassler@kit.edu)

Received: 30 January 2017 - Discussion started: 1 February 2017

Revised: 20 October 2017 - Accepted: 20 November 2017 - Published: 4 January 2018

\begin{abstract}
Transpiration is a key process in the hydrological cycle, and a sound understanding and quantification of transpiration and its spatial variability is essential for management decisions as well as for improving the parameterisation and evaluation of hydrological and soil-vegetationatmosphere transfer models. For individual trees, transpiration is commonly estimated by measuring sap flow. Besides evaporative demand and water availability, tree-specific characteristics such as species, size or social status control sap flow amounts of individual trees. Within forest stands, properties such as species composition, basal area or stand density additionally affect sap flow, for example via competition mechanisms. Finally, sap flow patterns might also be influenced by landscape-scale characteristics such as geology and soils, slope position or aspect because they affect water and energy availability; however, little is known about the dynamic interplay of these controls.
\end{abstract}

We studied the relative importance of various tree-, standand site-specific characteristics with multiple linear regression models to explain the variability of sap velocity measurements in 61 beech and oak trees, located at 24 sites across a $290 \mathrm{~km}^{2}$ catchment in Luxembourg. For each of 132 consecutive days of the growing season of 2014 we modelled the daily sap velocity and derived sap flow patterns of these 61 trees, and we determined the importance of the different controls.

Results indicate that a combination of mainly tree- and site-specific factors controls sap velocity patterns in the landscape, namely tree species, tree diameter, geology and aspect. For sap flow we included only the stand- and site- specific predictors in the models to ensure variable independence. Of those, geology and aspect were most important. Compared to these predictors, spatial variability of atmospheric demand and soil moisture explains only a small fraction of the variability in the daily datasets. However, the temporal dynamics of the explanatory power of the tree-specific characteristics, especially species, are correlated to the temporal dynamics of potential evaporation. We conclude that transpiration estimates on the landscape scale would benefit from not only consideration of hydro-meteorological drivers, but also tree, stand and site characteristics in order to improve the spatial and temporal representation of transpiration for hydrological and soil-vegetation-atmosphere transfer models.

\section{Introduction}

Transpiration makes up $65 \%$ of total terrestrial evapotranspiration and it is a key process in the hydrological cycle, but knowledge about transpiration fluxes in landscapes is still poor (Jasechko et al., 2013). While the main atmospheric drivers for transpiration are radiation and vapour pressure deficit, the most important terrestrial controls of this water flux are plant physiological properties and soil characteristics. The magnitude and dynamics of transpiration in turn affect the system's energy balance, soil water storage, groundwater recharge and stream flow (Barnard et al., 2010; Bond et al., 2002; Fahle and Dietrich, 2014; Moore et al., 2011; Pielke Sr., 2005). Spatial patterns of transpiration affect hy- 
drological processes and feedbacks within the catchment and are therefore important to consider in distributed hydrological modelling. While most of these models rely on estimates of evapotranspiration gained from meteorological measurements, for example using the Penman-Monteith equation, a better representation of spatio-temporal transpiration dynamics can inform model setups (Fenicia et al., 2016), serve for multi-response evaluation of models (Loritz et al., 2017; Scudeler et al., 2016) and improve model performance (Seibert et al., 2017). However, studies on the influences on spatial patterns of transpiration in landscapes are still scarce.

Methods to measure transpiration span a wide range of scales, from water and $\mathrm{CO}_{2}$-exchange measurements on individual leaves to characterisation of the convective boundary layer which integrates transpiration on a landscape scale. On the plot and stand-level scale, eddy-covariance techniques are applied, whereas on a tree scale, measuring xylem sap velocity and deriving sap flow by including an estimate of the sapwood area is a common method. Determining transpiration of stands using sap flow entails the challenges of reliably estimating whole-tree water use and applying appropriate empirical relationships when upscaling to stands (Köstner et al., 1998). However, for the investigation of the main controls for individual trees' water use, sap flow measurements are a suitable tool.

Atmospheric conditions and water availability are the main temporally variable abiotic controls for sap flow, influencing hourly, daily and yearly dynamics (Bovard et al., 2005; Clausnitzer et al., 2011; Ghimire et al., 2014; Granier et al., 2000; Oren et al., 1996; Schume et al., 2004). However, tree-, stand- or site-specific characteristics can also govern the magnitude of sap flow. Under similar external conditions, different tree species show contrasts in sap flow due to their different hydraulic architectures and mechanisms for coping with water stress (Bovard et al., 2005; Gebauer et al., 2012; Oren and Pataki, 2001; Traver et al., 2010). Tree diameter and thus tree size and crown area affects not only sap flow rates, but also radial sap velocity patterns (Bosch et al., 2014; Hölscher et al., 2005; Lüttschwager and Remus, 2007; Vertessy et al., 1995). Within stands, variation in sap velocity can occur because of competition for light and water resources, depending on the species composition (Cienciala et al., 2002; Dalsgaard et al., 2011; Gebauer et al., 2012; Oren and Pataki, 2001; Vincke et al., 2005).

On the landscape scale, site-specific characteristics such as geology, soil type, soil depth or depth to groundwater, elevation, slope position and aspect could potentially control spatial sap flow patterns because of their influence on water and energy availability. Many of these characteristics can be derived from maps and digital elevation models, and quantifying their importance is thus especially interesting for modelling purposes requiring landscape-scale transpiration. For instance, the geological setting and associated soil types determine soil water holding capacities, the location of the tree within the landscape's topography can influence its access to groundwater resources and the stand's microclimatic conditions, and differences of aspect also entail variation in energy input (Čermák and Prax, 2001; Vilhar et al., 2005). However, few studies have focused on the relative strength and possible temporal dynamics of these controls. While the impact of differences in accessible soil volume and groundwater depth on sap flow dynamics has been well described (Angstmann et al., 2013; Črmák and Prax, 2001; Tromp-van Meerveld and McDonnell, 2006), there have been few attempts to empirically use geological or soil units as large-scale proxies for water availability or potentially also for rooting depth limitations (Boer-Euser et al., 2016).

Slope position and elevation have been investigated at a few sites as site-specific controls of sap flow that possibly influence soil characteristics and microclimate. Bond et al. (2002) report no significant differences in sap flow with slope position for red alders and Douglas fir in Oregon, whereas Kumagai et al. (2007) found larger sap flux density values for cedars in a downslope stand compared to upslope trees; however, this effect was confounded by differences in tree size and stand structure, so that transpiration for the stands did not differ between the two slope positions. Similarly, in a drought-prone eucalypt forest in Australia, Mitchell et al. (2012) attribute lower sap flow values at their upslope plot compared to downslope positions to the differences in stand structure (lower basal area (BA) and sapwood area) and lower LAI. Otieno et al. (2014) compared two stands of subtropical evergreen forest in China at two different elevations and highlighted the structural differences of the two stands, but did not find differences in stand transpiration. However, differences were found among individual trees and were attributed to tree size as well as social position of the crown. Jung et al. (2014) studied the elevation effect in deciduous forests on a mountain slope in South Korea at three different elevations, at $450 \mathrm{~m}, 650 \mathrm{~m}$ and 950 a.m.s.1, and found a decrease of total annual canopy transpiration with elevation as a consequence of decreasing length of the growing season, and hence of differences in local climate. Maximum sap flux density of individual trees during clearsky days, however, did not vary significantly due to these effects. Using a geostatistical approach, Adelman et al. (2008) studied a suspected influence on transpiration due to differences in water availability on a slope inducing contrasts in species composition; however, they did not see this effect in the data, possibly because of overall seasonal dryness during the study period. Another study on controls of patterns of spatial autocorrelation in extensive sap flow dataset found the clear species influence on transpiration patterns; however, the effect of a slope-related moisture gradient could not be confirmed (Loranty et al., 2008), adding to the contrasting findings about the influence of slope position on transpiration we see in the literature. Even though hillslope aspect at least partially controls radiation input, sap flow studies on the influence of aspect are scarce. In a simulation study, Holst et al. (2010) examined water balances for two beech stands on 
opposite slopes in south-western Germany and found higher transpiration values for the south-west slope compared to the north-east slope, which the authors explained with the higher evaporative demand and higher precipitation input on that slope. Focusing on limits of atmospheric exchange, Renner et al. (2016) found that stand composition compensated for differences in sensitivities of sap velocity to evaporative demand on the south- and north-facing slopes of a valley transect, which led to overall similar transpiration rates on both slopes.

To summarise, the reported studies have shown that in addition to the obvious atmospheric and tree-scale physiological controls, site-specific characteristics can influence sap flow patterns in a landscape. So far this influence has mainly been studied as individual plot comparisons or on a seasonal basis. However, this approach does not provide information on the possible short-term, day-to-day changes in the importance of the different controls as a consequence of varying hydro-meteorological conditions. Yet estimating the dynamics of the various controls of sap flow is essential for understanding and predicting spatial patterns of transpiration on a landscape scale.

In this study we aim to explore daily spatial patterns of sap velocity and derived sap flow on the landscape scale, by applying multiple linear regression models and identifying the influence of tree-, stand- and site-specific characteristics that could be gained from maps or surveys and hence would be available for modelling purposes. We also examine the temporal dynamics of these influences and to what extent this can be linked to hydro-meteorological conditions. Our analysis is based on an extensive sap velocity dataset, measured on 61 beech and oak trees on 132 consecutive days in the growing season of 2014, spread over 24 locations in a $290 \mathrm{~km}^{2}$ catchment in Luxembourg.

\section{Methods}

\subsection{Study site}

The study site is located in the Attert catchment in western Luxembourg. The catchment covers three geological units (Fig. 1), predominantly Devonian schists of the Ardennes massif in the north-west, Triassic sandy marls, and a small area underlain by Luxembourg sandstone (Jurassic) on the southern catchment border (Martínez-Carreras et al., 2012). These different geological units gave rise to soils with different water retention properties. The soils on schists developed to haplic Cambisols, the soils on marls can be classified as different types of Stagnosols depending on their clay content of $20-60 \%$ and the sandy textures on the Luxembourg sandstone gave rise to Arenosols. The soils were classified according to the WRB classification system (IUSS Working Group WRB, 2006) and described further by Sprenger et al. (2016). Plant available water was determined from

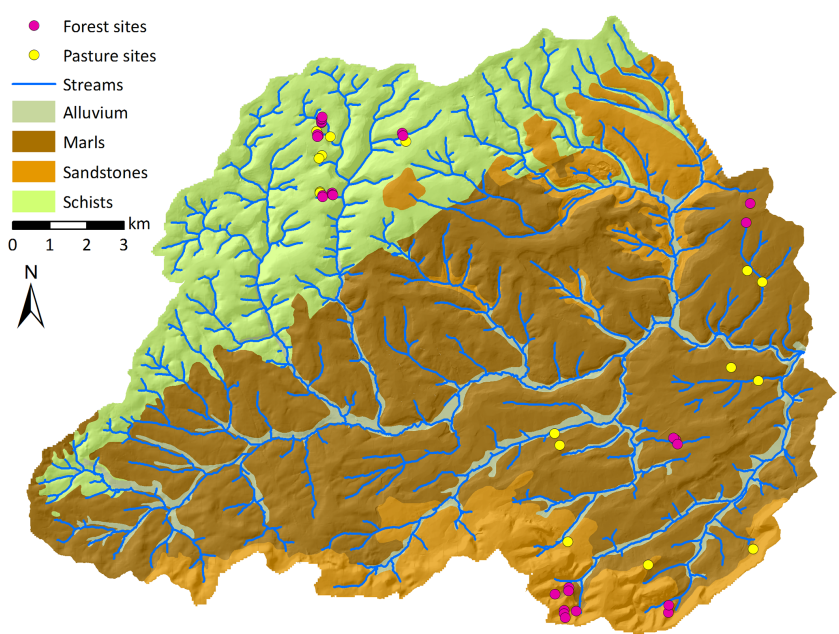

Figure 1. Map of the study site, the Attert catchment in Luxembourg.

mean water retention curves (using water tensions at $60 \mathrm{hPa}$ and $10^{4.2} \mathrm{hPa}$ ) based on 120 soil samples (Jackisch, 2015), amounting to $0.30 \mathrm{~m}^{3} \mathrm{~m}^{-3}$ for Cambisols and Stagnosols and $0.25 \mathrm{~m}^{3} \mathrm{~m}^{-3}$ for the Arenosols. However, the access to water is not only determined by the soil type. For example the Cambisols in the schist are very shallow and of high rock content. There are cracks filled with soil material in the underlying schist which could provide water for tree roots. The Stagnosols in the marl area are very clayey in the subsurface, probably limiting plant-available water resources and root penetration in these layers. We observed maximum rooting depths, averaged for each soil type, of $68 \mathrm{~cm}$ for the Cambisols, $90 \mathrm{~cm}$ for the Stagnosols and $98 \mathrm{~cm}$ for the Arenosols (Sprenger et al., 2016). Mean annual precipitation of the study area is approximately $850 \mathrm{~mm}$ (Pfister et al., 2000). Land use varies from mainly pasture and agriculture in the marl area and mainly forests in the sandstone to a mixture of agriculture and pasture on the plateaus and forests on the steep slopes of the schist area.

The catchment is the focus area of the CAOS (Catchments As Organised Systems) research unit which investigates landscape-scale structures, patterns and interactions in hydrological processes for model development (Zehe et al., 2014). A monitoring network of 45 sensor clusters was installed in 2012-2013, covering the different geological units, the land use types deciduous forest and pasture, and different slope positions and aspects. Measurements at the individual sites include meteorological parameters such as air temperature and humidity (Campbell CS215) and solar radiation (Apogee Pyranometer SP110) as well as soil moisture (Decagon 5TE) at three depths and three locations at each site. Sap flow is monitored with East 30 Sap Flow Sensors at all 29 forest sites.

The forests covered by the monitoring network mainly consist of mixed deciduous stands with European beech ( $\mathrm{Fa}$ - 
gus sylvatica L.), pedunculate and sessile oak (Quercus robur L. and Q. petraea (Matt.) Liebl., common hornbeam (Carpinus betulus L.), and a few maples (Acer pseudoplatanus L.) and alders (Alnus glutinosa (L.) Gaertn.). However, in this study only the most common species, beech and oaks, are considered. Identification to species level was not possible for the two oak species as they both occur in the study area, show morphologically intermediate forms and are possibly hybridised (Elsner, 1993; Zanetto et al., 1994). Our term "oak" refers to the whole group and we are aware that the oak species might differ somewhat in their transpiration characteristics, but the physiological contrast to beech trees should by far surpass these differences.

\subsection{Sap velocity measurements and calculation of sap flow}

The sites in the forest were characterised with a forest inventory on $20 \times 20 \mathrm{~m}^{2}$ plots, recording stem numbers, diameter at breast height (DBH) and BA for all trees with a circumference of more than $4 \mathrm{~cm}$, and tree height for a representative subset of the trees in the stand. Heights were gauged roughly as the canopy tops were not always clearly visible and we were interested in the social status of the trees rather than the precise height. Four trees per site were selected for sap flow sensor installation. The tree species and diameter were chosen to roughly represent the stand structure at the site but also allow a comparison to other sites where possible. Sap flow sensors were installed at breast height on the north-facing side of the stem and protected with a reflective cover to minimise the effects of radiation-induced changes in stem temperatures. After removing the bark, holes for the sensors were drilled using a drilling guide to ensure parallel installation of the sensor needles. The sensors, manufactured by East 30 Sensors in Washington, US, use the heat ratio method with a central heater needle and a thermistor needle upstream and downstream of the heater. Each thermistor needle contains three thermistors, at 5, 18 and $30 \mathrm{~mm}$ depth in the wood. Sap velocities $\left(V_{\text {sap }}\right.$ in $\left.\mathrm{m} \mathrm{s}^{-1}\right)$ at each of these locations are calculated from the temperatures measured at the corresponding thermistor pairs according to Eq. (1) (equations after Campbell et al., 1991):

$V_{\text {sap }}=\frac{2 k}{C_{w}\left(r_{\mathrm{u}}+r_{\mathrm{d}}\right)} \ln \left(\frac{\Delta T_{\mathrm{u}}}{\Delta T_{\mathrm{d}}}\right)$,

where $k$ is the thermal conductivity of the sapwood, set to $0.5 \mathrm{~W} \mathrm{~m}^{-1} \mathrm{~K}^{-1}, C_{\mathrm{w}}$ is the specific heat capacity of water $\left(\mathrm{J} \mathrm{m}^{-3} \mathrm{~K}^{-1}\right), r$ is the distance $(\mathrm{m})$ from the heater needle to the thermistor needle (in our case $6 \mathrm{~mm}$ ) and $\Delta T$ is the temperature difference $(\mathrm{K})$ before heating and $60 \mathrm{~s}$ after the heat pulse. Subscripts $u$ and $d$ stand for location upstream and downstream of the heater.

We corrected these values to account for wounding of the xylem tissue caused by the drilling according to the numerical model solutions for the heat pulse velocity method sug- gested by Burgess et al. (2001):

$V_{\mathrm{c}}=b V_{\mathrm{sap}}+c V_{\text {sap }}^{2}+d V_{\text {sap }}^{3}$,

where $V_{\mathrm{c}}$ is the corrected sap velocity $\left(\mathrm{m} \mathrm{s}^{-1}\right)$ and $b, c$ and $d$ are correction coefficients; for our $2 \mathrm{~mm}$ wounds we use $b=1.8558, c=-0.0018 \mathrm{~s} \mathrm{~m}^{-1}$ and $d=0.0003 \mathrm{~s}^{2} \mathrm{~m}^{-2}$ (Burgess et al., 2001). We used daytime sap velocity, averaged over a $12 \mathrm{~h}$ window from 08:00 to 20:00 LT. Our sensors provide measurements at three depths $(5,18$ and $30 \mathrm{~mm})$ within the sapwood, but because the sensors were not always ideally installed in the sapwood, we use the maximum value of these three depths' velocities for the sap velocity part of our analyses. The heat ratio method has been reported to underestimate high sap velocities (Vandegehuchte and Steppe, 2013; Fuchs et al., 2017), and the highly conductive earlywood vessels in the ring-porous oaks might exhibit locally high velocities. However, the trees in our study rarely reach the reported critical values and the oaks seem to plateau at even lower values, which is unlikely to be the result of sensor limitations.

Calculation of sap flow from sap velocity requires estimates of sapwood area and bark thickness. Sapwood area was calculated using the power law function for sapwood area based on $\mathrm{DBH}$, which was originally developed by Vertessy (1995). Coefficients for beech were taken from Gebauer et al. (2008), and for oak (Q. petraea (Matt.) Liebl.) from Schmidt (2007), yielding the following equations:

$A_{\mathrm{S}_{\_} \mathrm{B}}=0.778 \cdot \mathrm{DBH}_{\mathrm{B}}^{1.917}$,
$A_{\mathrm{S}_{-} \mathrm{O}}=0.065 \cdot \mathrm{DBH}_{\mathrm{O}}^{2.264}$,

with $A_{\mathrm{S}}$ for the sapwood area $\left(\mathrm{cm}^{2}\right), \mathrm{DBH}$ is the diameter at breast height $(\mathrm{cm})$, and subscripts are $\mathrm{O}$ for oak and $\mathrm{B}$ for beech.

The next step was to calculate the sapwood depth. From the whole-tree diameter we first subtracted an estimate for the bark to consider only the sapwood and heartwood part of the stem in the subsequent calculations. Bark thickness was estimated according to empirical relations developed by Rössler (2008):

$d_{\mathrm{b} \_\mathrm{B}}=2.61029+0.28522 \cdot \mathrm{DBH}_{\mathrm{B}}$,

$d_{\mathrm{b}_{-} \mathrm{O}}=9.88855+0.56734 \cdot \mathrm{DBH}_{\mathrm{O}}$,

where $d_{\mathrm{b}}$ is the double bark thickness (mm), DBH and subscripts are analogous to Eqs. (3) and (4).

Then we calculated the depth of the sapwood-heartwood boundary. As our sensors measure at the three depths 5, 18 and $30 \mathrm{~mm}$, we assigned the corresponding velocities to the stem sections $0-15$ and $15-25 \mathrm{~mm}$ and assumed a linear decline from $25 \mathrm{~mm}$ depth the up to the sapwood-heartwood boundary, using the $30 \mathrm{~mm}$ velocity as the maximum value of the linear decline (as used by Renner et al., 2016). The linear decline mainly applied to beech trees, as most of the smaller 
oaks' sap velocities at $30 \mathrm{~mm}$ depth were already zero. Daily sap flow for each tree was then derived by multiplying each depth's sap velocity (averaged over the $12 \mathrm{~h}$ from 08:00 to 20:00 LT as we did before) with the respective sapwood area sections.

We included sap flow in our analyses because, compared to sap velocity, it provides a better estimate of tree transpiration and is usually more of interest for hydrologists. It needs to be noted that the calculation relies on the published speciesspecific empirical relationships for sapwood area based on tree diameter (e.g. Gebauer et al., 2008; Meinzer et al., 2005; Vertessy et al., 1995). Other potential controls on transpiration such as topography or geology as proxies for rooting depth or water availability are not considered in these equations. As site characteristics can induce ecophysiological adaptations, for example in tree functional traits such as stomata density, xylem vessel diameters or hydraulic conductivity (Hajek et al., 2016; Stojnić et al., 2015), sapwood area properties might be similarly adapted to site conditions. However, to our knowledge there are no studies on the landscape scale yet which examine these adaptations.

Sap velocity is independent of these considerations; therefore, we mainly focus our analyses on this variable and use sap flow as a tentative comparison. For a more reliable way of estimating sap flow influences in a diverse landscape, the sapwood area would need to be measured directly for each tree.

\subsection{Auxiliary variables: estimating potential evaporation and water availability}

The main environmental limitations to sap flow are the atmospheric conditions (the solar heating of the leaves, water vapour pressure deficit, etc.) as the driving gradient for transpiration and the water supply to the trees. We assess these influences by using a thermodynamically derived measure for potential evaporation $E_{\text {pot }}$ which has been recently developed by Kleidon and Renner (2013) as well as the soil moisture observations at each sites as a measure of water availability.

Soil moisture was measured in three profiles per site at 10,30 and $50 \mathrm{~cm}$ depth. For our analyses we took the average across all depths and profiles to estimate the average soil moisture in the top $60 \mathrm{~cm}$ for each site.

$E_{\text {pot }}$ was calculated as follows (Kleidon and Renner, 2013):

$E_{\mathrm{pot}}=\frac{1}{\lambda} \frac{s}{s+\gamma} \frac{R_{\mathrm{sn}}}{2}$,

where $\lambda=2.5 \times 10^{6} \mathrm{~J} \mathrm{~kg}^{-1}$ is the latent heat of vaporisation, $s$ is an empirical approximation of the slope of the saturation vapour pressure curve, calculated as $s=s(T)=6.11 \cdot 5417$. $T^{-2} \cdot e^{19.83-5417 / T}$, with the temperature $T(\mathrm{~K})$. The psychrometric constant was approximated as $\gamma \approx 65 \mathrm{PaK}^{-1}$, and $R_{\mathrm{Sn}}$ $\left(\mathrm{W} \mathrm{m}^{-2}\right)$ is absorbed solar radiation. The air temperature was taken from the measurements within the stands at the forest sites. This gives room for some error, as the below-canopy temperature will differ from the above-canopy temperature. However, the temperature does not have very strong leverage in Eq. (7) and we would expect even larger errors if we were to use air temperature from nearby grassland sites because of the differences in microclimate and energy balance for the different land covers. Solar radiation features more prominently in the equation and therefore needs careful estimation. We use an approach deriving the above-canopy radiation from the digital elevation model of the catchment, using the GRASS GIS package "r.sun". This method corrects for latitude, day of year and topography and corresponds well with the measured radiation at the pasture sites for cloudless days. Dividing the r.sun-estimated radiation values with the measured radiation values at each pasture site yields correction factors for actual cloud conditions for each day. We apply this cloud correction to the r.sun values for the forests, using the pasture site that is closest to the respective forest sites. These latitude-, topography- and cloud-corrected radiation estimates are then used for calculating $E_{\text {pot }}$. Studying transpiration along a hillslope transect, Renner et al. (2016) found $E_{\text {pot }}$ comparable (if slightly underestimating) to a traditional Penman-Monteith approach and also tested for effects of vapour pressure deficit and wind speed. The results did not show distinct effects, and hence we used $E_{\text {pot }}$ as a robust measure, which is appropriate to the available atmospheric measurements in our study. We also used radiation measurements within and outside the stands to determine the period when the canopy is fully developed and only use this period for our analyses. For the year 2014 this period lasted from 11 May to 20 September, amounting to 132 days.

\subsection{Data analysis}

We selected a dataset of continuous sap velocity measurements from 61 trees located at 24 of the altogether 29 forest sites in the CAOS dataset. Each of the monitored trees was associated with tree-, stand- and site-specific properties. Tree-specific properties were the species, diameter at breast height (DBH) and tree height, whereas the stands were characterised by the measurements undertaken in the forest inventory, namely BA and median DBH of the stand as well as the number of stems recorded on the inventory plot. Additionally, there were several landscape attributes which could be associated with the monitored trees such as their position within one of the three geological units, their location on a hillslope and the aspect of that slope. These attributes could be considered as proxies for associated soil properties and energy availability, influencing water availability and potential evaporation. The site characteristics and species entered the linear models as categorical variables. An overview of the dataset is shown in Table 1, in which the class "no-slope" for slope position refers to slopes of less than $5^{\circ}$, which are located in the marl area. The class "no-aspect" for aspect in- 
cludes the same sites, but also flat downslope parts of four slopes in the schist and sandstone areas. Both classes probably describe landscape positions with shallower depth to groundwater than the other sites.

Potential evaporation and water availability are usually considered to be the main external dynamic controls of sap flow, so we examined their importance for the temporal variability in sap velocity by correlating the time series of sap velocity with $E_{\mathrm{pot}}$ and soil moisture, using the Spearman rank correlation. However, we were interested primarily in the spatial variability of sap velocity as a way to determine influences on transpiration patterns on the landscape scale. We assessed this by examining the spatially distributed dataset of daily-averaged sap velocity of the 61 trees, for each of the 132 days of our study period.

In a first step, we examined the individual influence of the different tree-, stand- and site-specific controls listed in Table 1 and of the external controls soil moisture and $E_{\text {pot }}$ on sap velocity at the respective forest sites, averaged across the study period, separately for each tree. This first analysis ignored multivariate interactions to get a simplified overview of the data; hence, effects seen in these comparisons should not be over-interpreted. For the categorical variables (species, geology, slope position and aspect) we also looked at possible temporal changes of differences in sap velocity between the categories by testing daily datasets with the Mann-Whitney $U$ test or the Kruskal-Wallis test, for variables consisting of three or two categories, respectively, to a significance level of $\alpha=0.05$.

The multidimensional effect of all tree-, stand- and sitespecific influences was then analysed with multiple linear regression models separately for each day. This modelling approach is meant to explore the main controls of sap velocity or sap flow patterns, but at this stage we do not aim at predicting these spatial patterns. The response variable for each of the 132 daily models was the log-transformed daily sap velocity of each tree, because the logarithmic values corresponded better to a normal distribution. The linear regression model can be expressed as

$\ln \left(V_{\text {sap }}\right)=\beta_{0}+\sum_{i=1}^{n} \beta_{i} x_{i}$,

with $n$ predictors $\left(x_{0}, \ldots x_{i}\right)$ and the regression coefficients $\left(\beta_{0}, \ldots \beta_{i}\right)$ estimated to obtain an optimum fit.

Before applying the regression models, we checked the predictors for collinearity by determining the correlation matrix. There was only one combination of predictors with a Spearman rank correlation coefficient above the widely employed critical value of collinearity, $|\rho|>0.7$ (Dormann et al., 2008; Tannenberger et al., 2010), the number of stems and median diameter of the stand, at $\rho=-0.73$. The effects of this correlation on the linear models was tested by running the models for both the original set of predictors and again, leaving out number of stems. As the results did not differ with respect to the variance contributions of the different predictors, we kept all predictors in the final analysis. We also did not include interaction terms in the final models because after testing with various interactions, these did not contribute much to the explained variance.

Although a step-wise simplification of the models using the Akaike information criterion led to a higher percentage of explained variance by the models, we refrained from using this simplification in order to keep the model structures similar for each day to allow comparability of the temporal, dayto-day changes in predictor importance. For prediction, the potentially best model would be more appropriate; however, in our exploratory analysis we focused on comparability. The relative importance of the predictors for explaining the observed variance of sap velocity or sap flow was assessed using the approach of Grömping (2007), made available in the R package "relaimpo". Of the different built-in methods to determine relative importance, we used "lmg". This method uses sequential sums of squares from the linear model, applies all possible orderings of regressors and obtains an overall assessment by averaging over all orders, which is deemed appropriate for causal interpretation and unknown weights of the different predictors (Grömping, 2007). The initial order of the predictors in the linear models is not relevant for the relative importance as orderings are shuffled.

Over-fitting can be a problem in linear models with many predictors. We checked for this by performing a comparison between the residual standard error (RSE) of the original models and the root mean square error (RMSE) of a 10-fold cross-validation (Fig. 2). In case of over-fitting, the RMSE of the cross-validation should be much higher than the RSE. In our case, both error measures differed only marginally and were largest when sap velocities were small. These were the days when the linear model generally failed to explain the variance in the datasets. For days with high sap velocities, the small errors as well as the small difference between RSE and RMSE indicated that the models are not over-fitted. Additionally, Fig. 2 showed that limiting the analysis to the period of fully developed canopy excludes periods of larger errors at the beginning and end of the season.

The linear models for sap velocity give an indication about possible controls of transpiration; however, a more intuitive measure for transpiration is sap flow. Therefore, as an indication of how the actual transpiration patterns are influenced by site- and stand-specific characteristics, we repeated the multiple linear regression analysis with the derived sap flow dataset. The calculation from sap velocity to sap flow is based on the species-specific relations between sapwood and DBH, so we did not use species, DBH and height as predictors in the linear models for sap flow as they are not independent anymore. We only used the remaining stand- and site-specific predictors as well as $E_{\text {pot }}$ and soil moisture.

We analysed the temporal dynamics of the variance contributions of the individual predictors and of the proportion of variance explained by all the tree-specific predictors (only 
Table 1. Overview of the characteristics associated with the trees in the sap velocity dataset. These are used as predictors in the multiple linear regression. Abbreviations are DBH for diameter at breast height, BA for basal area of the stand.

\begin{tabular}{llll}
\hline Property & Group & Class (and no. of trees in each class) & Value (25/50/75 percentile) \\
\hline Species & Tree-specific & beech (39), oak (22) & \\
DBH $(\mathrm{cm})$ & Tree-specific & & $34 / 46 / 63$ \\
Height $(\mathrm{m})$ & Tree-specific & & $24 / 29 / 34$ \\
BA $\left(\mathrm{m}^{2} \mathrm{ha}^{-1}\right)$ & Stand-specific & & $27 / 40 / 54$ \\
Median DBH $(\mathrm{cm})$ & Stand-specific & & $5 / 14 / 28$ \\
No. of stems & Stand-specific & & $20 / 24 / 43$ \\
Geology & Site-specific & marl (13), sandstone (22), schist (26) & \\
Slope position & Site-specific & upslope (41), downslope (9), no-slope (11) & \\
Aspect & Site-specific & north (17), south (29), no-aspect (15) & \\
\hline
\end{tabular}

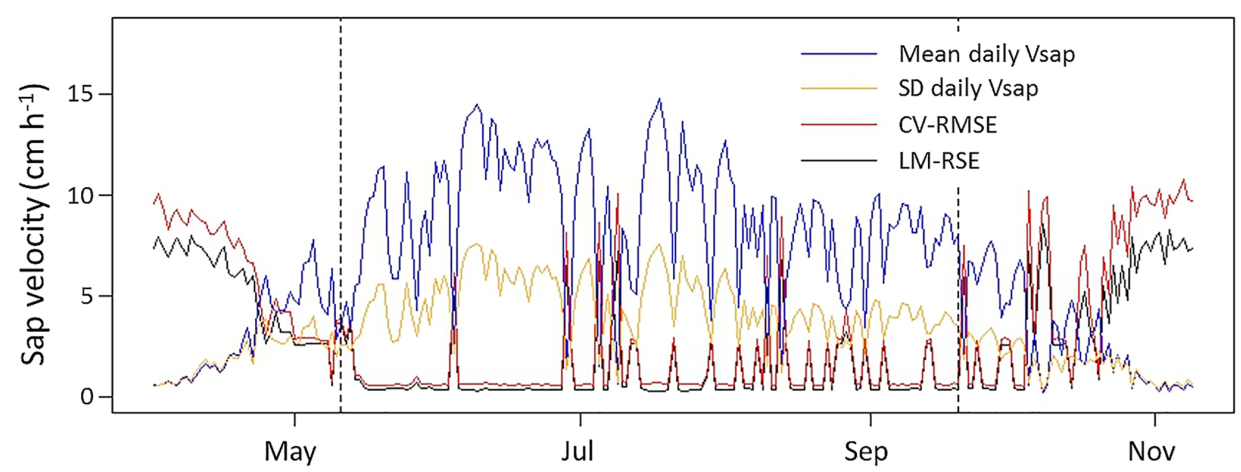

Figure 2. Comparison of residual standard error of the original linear models (LM-RSE) and the root mean square error of a 10-fold crossvalidation (CV-RMSE), in relation to mean and standard deviation of daily sap velocities $\left(V_{\text {sap }}\right)$. The dashed lines indicate the beginning and end of the focus period with a fully developed canopy.

for sap velocity) taken together, all the stand-specific predictors taken together and all the site-specific predictors taken together. We also correlated these time series to catchmentaveraged time series of soil moisture and $E_{\mathrm{pot}}$ as indicators of general atmospheric demand and water availability, using the Spearman rank correlation. All statistical analyses were carried out in the language and environment $\mathrm{R}$ ( $\mathrm{R}$ Development Core Team, 2014).

\section{Results}

\subsection{Controls of temporal dynamics of sap velocity}

Correlations of time series of sap velocity for each tree with $E_{\text {pot }}$ and soil moisture yielded high positive and significant $(\alpha=0.05)$ Spearman rank correlations for $E_{\text {pot }}$, but correlations to soil moisture were slightly negative and very weak (Fig. 3).

\subsection{Controls of spatial patterns in daily mean sap velocity and sap flow}

A first simplified overview of the influence of the various factors on sap velocity patterns was derived from plotting sap
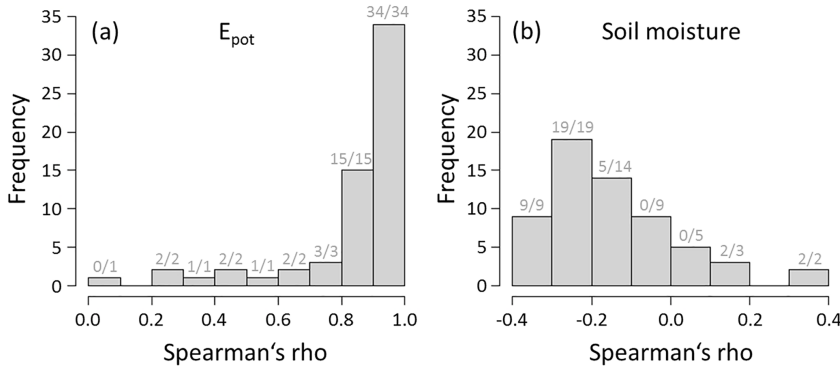

Figure 3. Histograms of temporal correlations between (a) $E_{\text {pot }}$ and (b) soil moisture at each site with sap velocity for the 61 trees in the dataset. The small numbers in grey on top of the bars indicate how many of the correlations in the specific group are significant.

velocity, averaged over the entire study period for each tree, against the factors or their respective categories (Fig. 4). Obviously, this graph neglects the combined influence of the interplay of all these factors, but yields a first overview of the data and possible relations. For example, the difference between higher sap velocities in beech trees compared to oaks can be seen as well as a possible positive relation between sap velocity and DBH or tree height. In the category for aspect, 

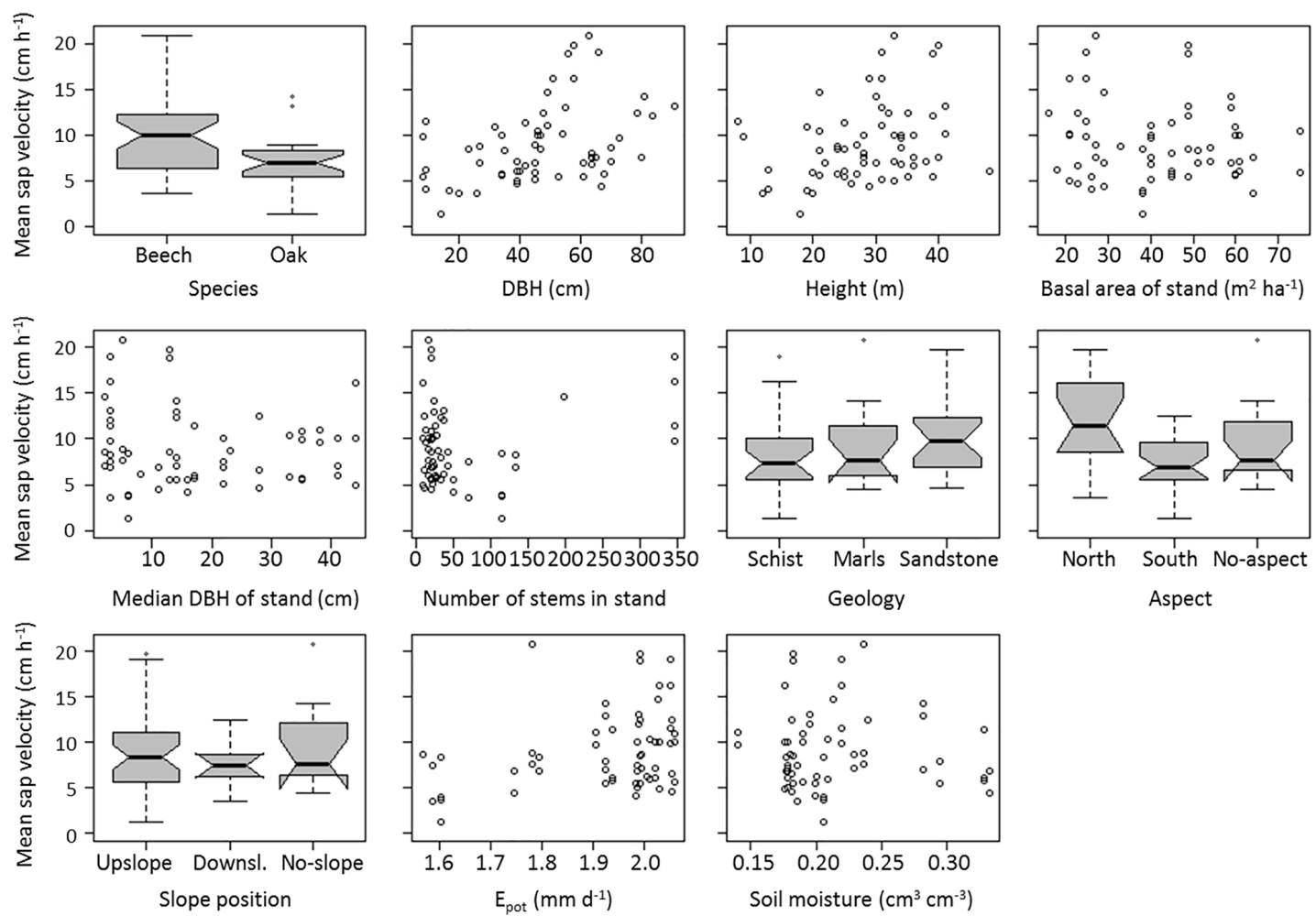

Figure 4. Univariate influence of each predictor on sap velocity means for each tree over the entire study period. Box plot parameters are as follows: the horizontal line within the box visualises the median, boxes comprise data between the 1st and 3rd quartile of the data, whiskers reach to $1.5 \times$ the interquartile range outside the box (or to the maximum/minimum value if smaller/larger), circles stand for outliers or data points outside the whiskers, notches show approximately $95 \%$ confidence intervals around the medians.
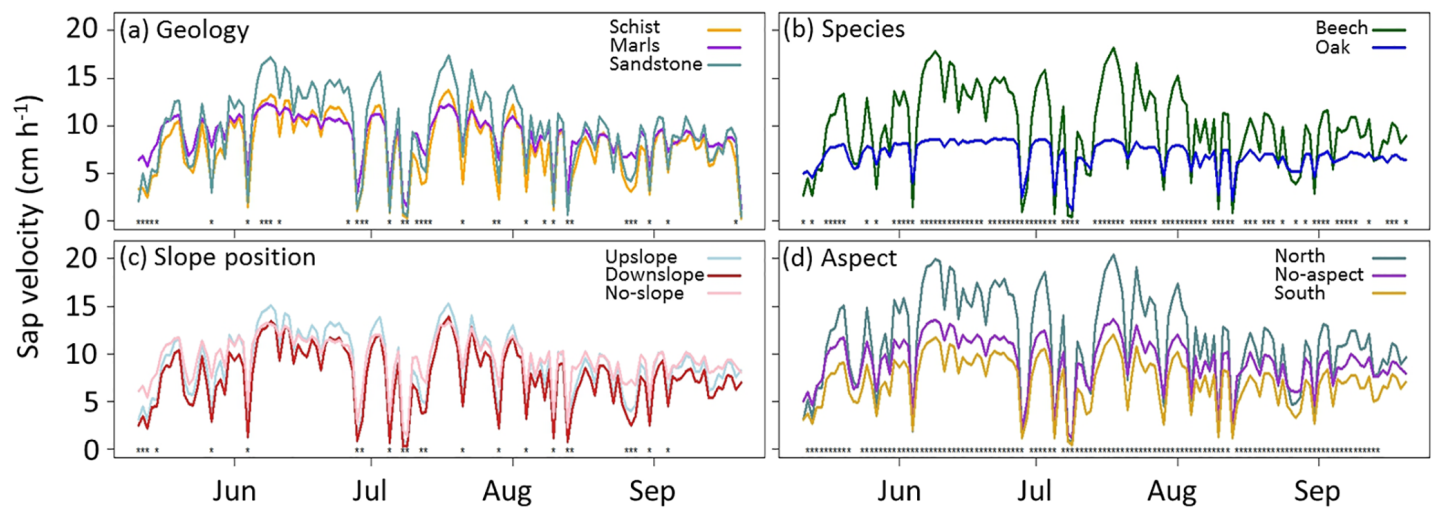

Figure 5. Differences between sap velocities depending on (a) geology, (b) species, (c) slope position and (d) aspect. Lines show the average dynamics of each class. Asterisks at the bottom of the panels indicate significant differences for that day according to Mann-Whitney $U$ or Kruskal-Wallis tests at $\alpha=0.05$, for differences between the two or three categories, respectively.

the box plots show a difference between higher sap velocities on north-facing slopes compared to south-facing ones, with trees located in plains having somewhat intermediate velocities.

The categorical factors were assessed in more detail looking at temporal changes in sap velocity differences. Statistical tests (Mann-Whitney $U$ test for two and Kruskal-Wallis for three categories, $\alpha=0.05$ ) applied to the sap velocity datasets for each day for the example of the categorical factors geology, species, slope position and aspect showed significant differences (Fig. 5). There is in particular a significant difference between south- and north-facing slopes and between beech and oak trees for most days of the dataset (Fig. 5), providing a first indication of the importance of both 


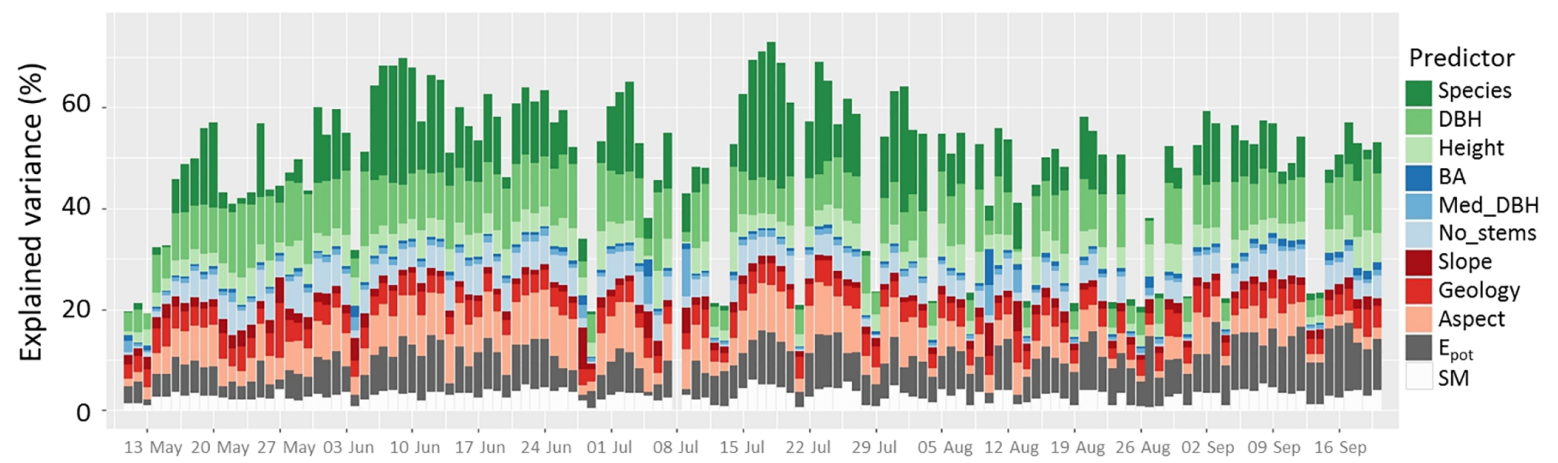

Figure 6. Proportion of variance explained by the different predictors in the daily linear models of spatial sap velocity patterns: 132 daily models from 61 trees at 24 sites.
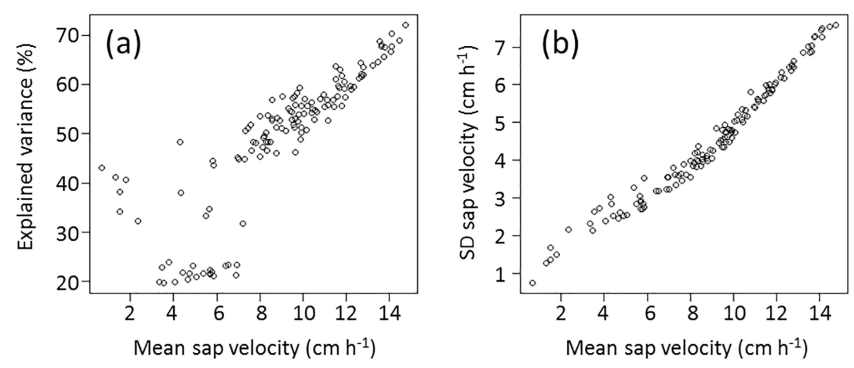

Figure 7. (a) Explained variance of the linear models in relation to mean sap velocities for all 132 days of the study period and (b) standard deviation of sap velocity depending on mean sap velocities for those 132 days.

tree- and site-specific influences. In contrast, there were only 36 of 132 days showing significant differences for geology and 25 days for slope position, occurring when sap velocities were generally low.

In a more comprehensive approach, we assessed the combined effect of the various tree-, stand- and site-specific influences on sap velocity with the help of multiple linear regression generating 132 daily models describing the spatial patterns. The total explained variance for the sap velocity models ranged from $20 \%$, on days when the models fail to explain the spatial variability in the dataset, to $72 \%$, which constitutes fairly good explanatory power (Fig. 6). The total explained variance correlated strongly with catchment averages of sap velocity (Pearson's $r=0.84, p<0.001$ ), especially at sap velocities $>7 \mathrm{~cm} \mathrm{~h}^{-1}$ (Fig. 7). Spatial variability of sap velocity in the catchment, expressed as standard deviation of the daily values for the 61 trees, also increased with increasing mean sap velocity (Pearson's $r=0.98, p<$ 0.001; Fig. 7). The consistent model structure showed that the change in the proportion of explained variance over time was different for the various predictors (Fig. 6). Averaged across the 132 daily models, $9 \%$ of the variance was explained by species, $9 \%$ by $\mathrm{DBH}$ and $4 \%$ by tree height. Characteristics of the stand yielded $1 \%$ for BA, $1 \%$ for me- dian DBH and $4 \%$ for number of stems, and the site-specific predictors amounted to $2 \%$ for slope position, $4 \%$ for geology and $6 \%$ for aspect. The external dynamic controls of sap flow, $E_{\text {pot }}$ and soil moisture, explained 7 and $3 \%$ of the variance in daily sap velocity patterns, respectively.

The contribution of the different predictors to the overall explained variance of the linear models varied strongly from day to day. On days when average and spatial variability of sap velocity was low the models performed badly. There were some predictors which showed larger fluctuations, for example species, compared to more constant contributions from predictors like the number of stems or DBH (Fig. 6).

The multiple linear regression models for sap flow patterns explained between 18 and $56 \%$ of the variance in the daily datasets (Fig. 8), on average $49 \%$. Averaged across the 132 daily models, the stand-specific predictors explained $8 \%$ of the variance $(4 \%$ by BA, $1 \%$ by median DBH and $3 \%$ by the number of stems). The largest contribution came from geology with $21 \%$, then aspect with $10 \%$, while slope position only explained $3 \%$. $E_{\text {pot }}$ and soil moisture explained 7 and $1 \%$ of the variance, respectively, which is comparable to their contributions in the linear models for sap velocity patterns.

The variance contributions stayed fairly constant in time, except for days when the models failed to explain the spatial variability in the data altogether (Fig. 8). Compared to the linear models for sap velocity, the models for sap flow had less explanatory power. The contributions of the standspecific predictors were not very important, similar to the results for sap velocity. For the site-specific controls, the largest contribution came from geology, and less from aspect; in contrast, in the sap velocity models, aspect explained a larger proportion of the variance than geology (Fig. 8).

\subsection{Temporal dynamics of predictor importance}

Comparing the dynamics of the proportion of variance explained by all the tree-specific predictors taken together, all the stand-specific predictors taken together and all the site- 


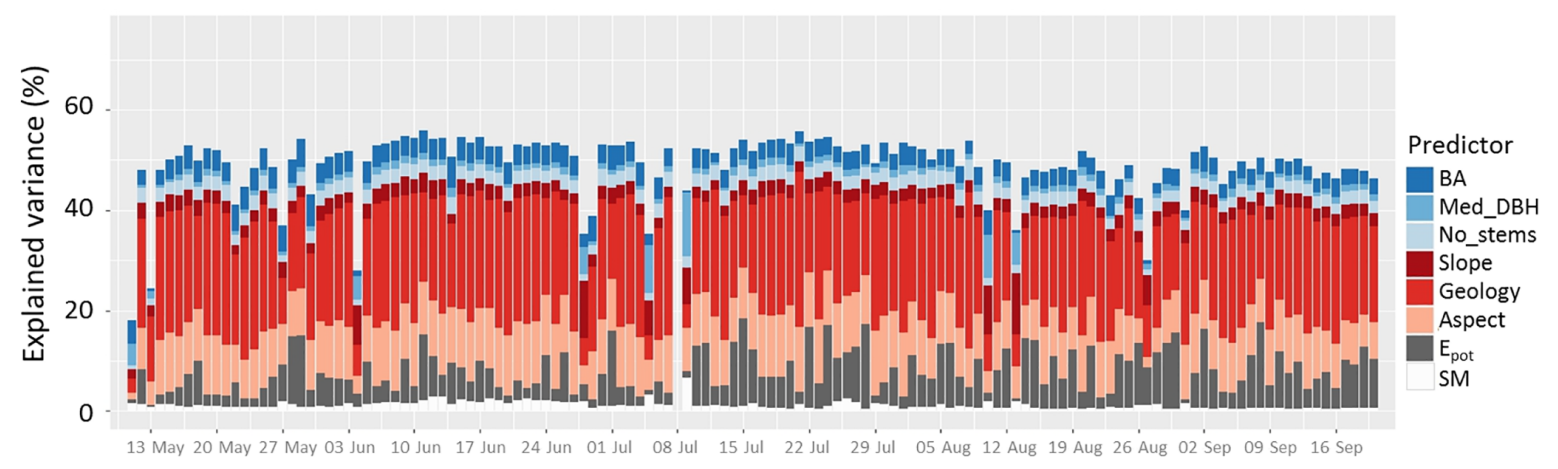

Figure 8. Proportion of variance explained by the different predictors in the daily linear models of spatial sap flow patterns: 132 daily models from 61 trees at 24 sites.

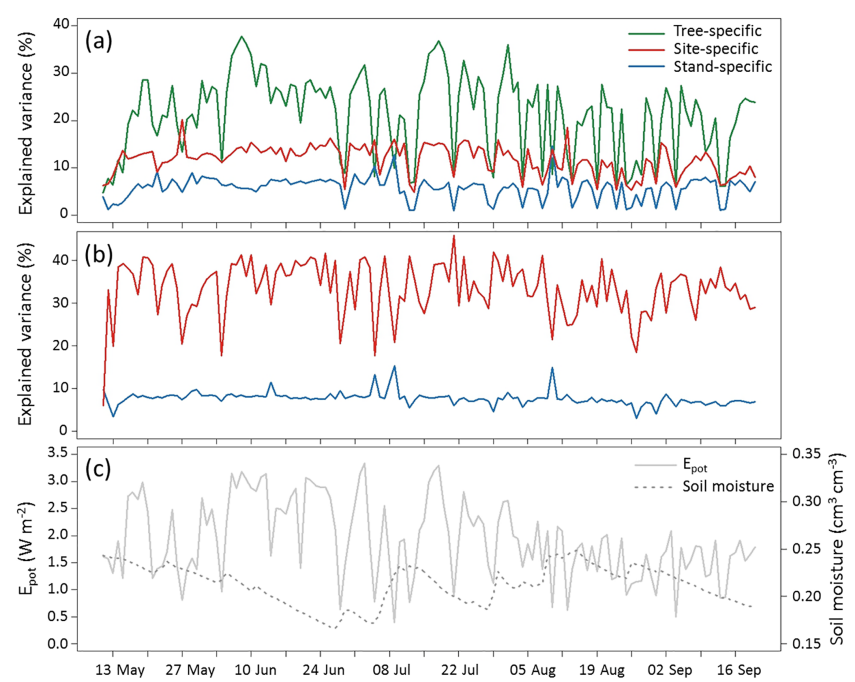

Figure 9. Explained variance of the daily linear models, separated according to the predictor groups used in the regression, (a) for sap velocity and (b) for sap flow. (c) Catchment average of soil moisture and potential evaporation $E_{\text {pot }}$.

specific predictors taken together to the catchment-average dynamics of $E_{\mathrm{pot}}$ and soil moisture (Fig. 9) showed that the stand- and site-specific predictors' contributions stayed relatively constant apart from the days when the model failed. This was the case for both the sap velocity and the sap flow models. In contrast, the tree-specific predictors in the sap velocity models varied to a greater extent. Visual comparison indicated a link between fluctuations of tree-specific influences and potential evaporation $\left(E_{\mathrm{pot}}\right)$, but not soil moisture (Fig. 9).

The Spearman rank correlations of the predictors' explained variance with $E_{\text {pot }}$ and soil moisture, listed in Table 2, also confirmed that changes in species influence in the sap velocity were strongly linked to changes in $E_{\text {pot }}$, with a significant correlation of $r=0.81$. Further weaker but significant correlations were detected between $E_{\text {pot }}$ and number of stems at $r=0.50$, aspect at $r=0.67$ and soil moisture at $r=0.55$, respectively. Summarised into categories, the influence of tree-specific predictors strongly correlated with $E_{\text {pot }}(r=0.86)$; similarly, there was a strong correlation of the overall explained variance with $E_{\mathrm{pot}}(r=0.84)$. Some of the correlations with soil moisture were significant, but they were mostly weak, with $|r|<=0.37$.

In the sap flow models, the only significant correlations worth mentioning were between $E_{\text {pot }}$ and aspect and between $E_{\text {pot }}$ and the overall explained variance, at $r=0.57$ and $r=$ 0.72 , respectively.

\section{Discussion}

\subsection{Controls of temporal dynamics of sap velocity}

The strong positive temporal correlation of sap velocity and $E_{\text {pot }}$ (Fig. 3) confirms the well-known role of the atmospheric controls as the main external drivers for transpiration (Bovard et al., 2005; Clausnitzer et al., 2011; Granier et al., 2000; Jonard et al., 2011). Soil moisture, however, did not affect the temporal dynamics of sap velocity in a similar way (Fig. 3). One reason for this surprisingly weak relation could be that water is not a limiting factor for transpiration in this landscape, or at least not during the observed time period. In the schist area of the catchment, anecdotal evidence given by forest wardens suggests that beech trees on south-facing slopes are indeed water-stressed during dry, hot summer months, although in our data we did not see a limitation of sap velocity for the beech trees. A different explanation for the lack of correlation is that soil moisture in the top $60 \mathrm{~cm}$ of the soil profile is simply not a sufficiently good proxy for water availability. In the soils of the schist there might be additional water resources stored in the weathered bedrock or the schist fractures which could be accessible to roots reaching deeper than the maximum rooting depths estimated from power drill cores in the study area (Sprenger et al., 2016). In the deep sandstone soils with maximum observed rooting depths of $98 \mathrm{~cm}$ in the drill cores (Sprenger et al., 2016), roots could 
Table 2. Spearman rank correlation between the time series of the different predictors' explained variance and the time series of potential evaporation $\left(E_{\text {pot }}\right)$ and soil moisture. Values in bold are significant correlations (at $\alpha=0.05$ ).

\begin{tabular}{lrr|rr}
\hline & \multicolumn{2}{c|}{ Sap velocity } & \multicolumn{2}{c}{ Sap flow } \\
Predictor & $E_{\text {pot }}$ & Soil moisture & $E_{\text {pot }}$ & Soil moisture \\
\hline Species & $\mathbf{0 . 8 1}$ & $\mathbf{- 0 . 3 0}$ & & \\
DBH & $\mathbf{0 . 3 2}$ & -0.14 & & \\
Height & 0.11 & -0.05 & & \\
BA & -0.15 & -0.05 & $\mathbf{0 . 4 4}$ & $\mathbf{- 0 . 0 9}$ \\
Median DBH & $\mathbf{0 . 4 4}$ & -0.16 & $\mathbf{0 . 3 4}$ & $\mathbf{0 . 0 0}$ \\
No. of stems & $\mathbf{0 . 5 0}$ & $\mathbf{- 0 . 3 5}$ & $\mathbf{0 . 4 4}$ & $\mathbf{- 0 . 0 3}$ \\
Slope & $\mathbf{- 0 . 3 2}$ & $\mathbf{0 . 2 1}$ & $\mathbf{0 . 2 2}$ & $\mathbf{- 0 . 0 1}$ \\
Geology & 0.04 & $\mathbf{0 . 1 8}$ & $\mathbf{0 . 3 5}$ & -0.20 \\
Aspect & $\mathbf{0 . 6 7}$ & $\mathbf{- 0 . 3 7}$ & $\mathbf{0 . 5 7}$ & -0.38 \\
$E_{\text {pot }}$ & $\mathbf{0 . 3 4}$ & $\mathbf{- 0 . 1 8}$ & 0.10 & $\mathbf{0 . 0 4}$ \\
Soil moisture & $\mathbf{0 . 5 5}$ & $\mathbf{- 0 . 3 0}$ & $\mathbf{0 . 2 5}$ & -0.21 \\
\hline Tree-specific & $\mathbf{0 . 8 6}$ & $\mathbf{- 0 . 3 4}$ & & \\
Stand-specific & $\mathbf{0 . 2 8}$ & $\mathbf{- 0 . 3 3}$ & $\mathbf{0 . 4 2}$ & $-\mathbf{0 . 0 7}$ \\
Site-specific & $\mathbf{0 . 3 5}$ & -0.14 & $\mathbf{0 . 4 6}$ & -0.26 \\
\hline Total exp. var. & $\mathbf{0 . 8 4}$ & $\mathbf{- 0 . 3 8}$ & $\mathbf{0 . 7 2}$ & -0.37 \\
\hline
\end{tabular}

also reach deeper, exploiting larger soil volumes or possibly tapping groundwater. The mostly flat marl areas exhibit shallow groundwater tables, so water limitation is unlikely for longer periods during the year. Thus, although water availability is an important boundary condition for transpiration, soil moisture measurements for the top $60 \mathrm{~cm}$ might not be an appropriate proxy, and including available information on groundwater levels or soil moisture in deeper layers could be useful in that regard.

\subsection{Controls on spatial patterns in daily mean sap velocity and sap flow}

Even from the simplified univariate assessment, the influence of characteristics such as species, DBH and aspect on spatial sap velocity patterns is visible (Fig. 4). In the more comprehensive approach applying multiple linear regression models to the daily sap velocity datasets, the combined effect of tree-, stand- and site-specific predictors surpasses by far the explanatory power of the boundary conditions, as $E_{\text {pot }}$ and soil moisture (Fig. 6) together explained only around $10 \%$ of the variance in sap flow patterns (Fig. 6). From the larger spatial variability of soil moisture (average of spatial standard deviation of $5 \% \mathrm{vol}$, compared to an average of temporal standard deviation of $2 \%$ vol) some influence on spatial sap velocity patterns might have been expected. But similar to the lack of temporal correlation with soil moisture, the lack of importance for spatial variability could result from the fact that measurements in the top $50 \mathrm{~cm}$ of the soil column were not meaningful to assess water availability at the sites or that a soil moisture limitation was not occurring in the observation period. $E_{\text {pot }}$ held larger explanatory power, but com- pared to the importance for temporal variability in sap velocity, the spatial effect was very small, possibly because the range of spatial variability in $E_{\mathrm{pot}}$ is much smaller. (The average of spatial standard deviation of $E_{\mathrm{pot}}$ was $0.18 \mathrm{~W} \mathrm{~m}^{-2}$, whereas the average of its temporal standard deviation was $0.73 \mathrm{~W} \mathrm{~m}^{-2}$ ). The same argument holds true for the similarly low proportion of explained variance by $E_{\mathrm{pot}}$ in the linear models for sap flow. This suggests that spatial patterns of (evapo)transpiration for distributed hydrological models based on meteorologically derived estimates only reflect a small part of the spatial variability of measured transpiration.

The explained variance of the tree-specific characteristics amounted to $22 \%$ averaged over the 132 sap velocity models (Fig. 6). Mechanisms underlying the differences in sap flow related to species, tree diameter and height have been studied in great detail in the field of tree physiology. The species contrast in our case consists of higher sap velocities for beech, as beech shows physiological advantages in transpiration efficiency and outperforms oaks in sufficiently moist conditions (Hölscher et al., 2005). Sap flow contrasts are even more pronounced because the active sapwood of oaks is limited to the outermost few annuli whereas for larger beech trees it can easily reach a depth of $7 \mathrm{~cm}$ or more (Gebauer et al., 2008). This limitation for oaks is visible in the species-specific allometric equations for sapwood area (Eqs. 3 and 4), but additionally, sap velocity in the innermost of our sensors (at $30 \mathrm{~mm}$ into the tree) was frequently zero for oaks. As expected, forest species composition is a major determinant of transpiration patterns (e.g. Hernandez-Santana et al., 2015; Loranty et al., 2008).

Tree height and DBH contrasts probably reflect the differences in social status, with larger, dominant trees reaching higher transpiration values than understorey trees. That larger trees, both taller and with larger DBH, exhibit higher sap velocities is likely due to their associated larger canopy and root volume, ensuring on the one hand the exposure of the leaves to the atmospheric gradient and on the other hand having access to a larger soil volume and potential water supply (Bolte et al., 2004; Nadezhdina and Čermák, 2003). For sap flow, the contrasts are again even larger than for sap velocity, because not only is larger DBH associated with larger velocities, but according to Eqs. (3) and (4), larger DBH also entails larger sapwood area, multiplying the effect of the sap velocity differences. Implementing spatial patterns of tree sizes into hydrological models could be attempted using mapped information from forest inventories, management plans or even lidar images (Ibanez et al., 2016; Rabadán et al., 2016; Vauhkonen and Mehtätalo, 2015). The stand density, expressed as the number of stems, explained on average $4 \%$ of the variance in the daily models for sap velocity and $3 \%$ for sap flow. Decreasing sap velocities with increasing stand density hints at the competition for light and resources among individual trees (Cienciala et al., 2002; Dalsgaard et al., 2011; Gebauer et al., 2012; Oren and Pataki, 2001; Vincke et al., 2005). However, due to this small contribution 
in the linear models, the stand-specific influence should not be over-interpreted. Basal area contributed on average $4 \%$ to sap flow models and hints at the same mechanisms as stand density.

The site-specific predictors together explained on average $12 \%$ of the spatial variance in the sap velocity models and $34 \%$ in the sap flow models (Figs. 6 and 8). Landscape characteristics such as topography and geology will control sap velocity patterns of otherwise homogeneous forests because they influence spatial patterns of either water or energy availability. Topography primarily controls radiation input, and to some extent water availability through depth to groundwater and soil characteristics, while geology mainly controls root distribution and water availability because it determines the depth to bedrock and depth to groundwater as well as soil type and soil depth. The effect of soil depth on transpiration, for example, has been shown by Tromp-van Meerveld and McDonnell (2006) for soils of the same type on the Panola hillslope, and the contrasts between different geological units in the Attert basin are likely to be even more pronounced. The soils in the schist area are very shallow, restricting rooting depth to an average of $68 \mathrm{~cm}$ (Sprenger et al., 2016). Together with moderate values for plant-available water (Jackisch, 2015), which are probably even lowered by the high rock content, this could lead to the smaller sap velocities in the schist compared to the sandstone or marls. These differences in soil depth and water retention characteristics manifest in differences in hydrological characteristics such as water storage dynamics, leading to contrasting runoff generation mechanisms for schist, marl and sandstone areas in the Attert catchment (van den Bos et al., 2006; Wrede et al., 2015). In turn, these geology-induced contrasts in depth to groundwater and water storage control tree access to these water reservoirs and favour species with adapted rooting systems (Dalsgaard et al., 2011), thus introducing a landscapescale effect on sap flow. We see this effect in the sap velocity models and even more in those for sap flow, suggesting that including geological maps into distributed hydrological models could be helpful not only for soil and bedrock characteristics but also for transpiration patterns.

The influence of aspect (Figs. 6 and 8) was mainly due to the south-facing slopes having smaller sap velocities and sap flow values compared to north-facing slopes (Fig. 5d). This is an apparent contradiction to the expectation that the larger energy input on the south-facing slopes should induce larger transpiration values. One explanation could be that energy input is not a limiting factor for transpiration in this landscape, but on the contrary, larger energy input on southfacing slopes might make them more prone to water limitation (Holst et al., 2010), especially when combined with other limiting factors. For example, the schist area holds a large proportion of south-facing slopes in our dataset and also has shallow soils due to the geological substrate, possibly exacerbating water limitation. However, as we did not see acute signs of water limitation in our data, the contrast in sap veloc- ities due to aspect would have to be long-term physiological adaptations (Hajek et al., 2016; Stojnić et al., 2015) to the drier conditions on south-facing slopes (as they are reported by forest wardens). The dominance of geology compared to aspect in the sap flow models could then result from a physiological effect of aspect influencing sapwood area or wood properties, which would then already be considered in the sap flow values, leaving geology as an independent predictor more important for spatial patterns in sap flow. A second explanation for the higher sap velocity and sap flow values on north-facing slopes (irrespective of species; see Appendix Fig. A1) can be seen in the exact locations of the trees. We would expect the larger $E_{\text {pot }}$ and sap velocity values to be on the south-facing slopes due to the higher radiation input. However, the values for $E_{\text {pot }}$ are calculated at the respective tree sites and these are not necessarily at the same relative positions on the slopes. So the $E_{\text {pot }}$ values are probably not directly related to aspect, but to the location within the valley, shading effects, etc. Grouping the $E_{\text {pot }}$ values according to aspect (Appendix Fig. A2), the main contrast occurs between north-facing slopes having higher values compared to no-aspect, whereas north- and south-facing slopes do not show considerable differences. Furthermore, as already mentioned before, spatial variability in the $E_{\mathrm{pot}}$ dataset are generally not very pronounced. Thus, a situation where the study trees are situated at more extreme locations with respect to aspect will probably induce a larger effect from $E_{\text {pot }}$. We suspect that the latter explanation is more relevant for the aspect differences in our data. A more targeted study including wood properties and stronger aspect contrasts would be needed to clarify this issue (and is in progress).

Slope position did not play a major role in explaining spatial sap velocity patterns (Figs. 6 and 8) although due to its possible effect on soil depth, water availability and species composition it is also the best-studied of the three site properties we included in our models (Adelman et al., 2008; Bond et al., 2002; Kumagai et al., 2007; Loranty et al., 2008; Mitchell et al., 2012). A reason for this lack of explanatory power could be that the information within this variable is partly also included in aspect because both the aspect category "no-aspect" and the slope position categories "no-slope" and "downslope" suggest sites which are close to groundwater resources. In a way, all three site-specific influences, geology, aspect and slope position, can be regarded as proxies for underlying characteristics of water availability.

\subsection{Temporal dynamics of predictor importance}

Understanding the feedback of spatial transpiration patterns with hydrological processes requires assessment of the temporal dynamics of the controls of these patterns, for example on a seasonal or daily basis. Our analyses indicate that spatial sap velocity patterns are governed by mainly tree- and site-specific characteristics. For the sap flow models, species and DBH were excluded as predictors because they were part 
of the calculation of sap flow. The resulting patterns were mainly controlled by site-specific characteristics; stand characteristics played a negligible role. The temporal shifts in these controls depend on hydro-meteorological conditions, especially potential evaporation (Fig. 9). And whereas the direct influence of hydro-meteorological variability on sap flow has been highlighted in many studies (Bovard et al., 2005; Clausnitzer et al., 2011; Granier et al., 2000; Jonard et al., 2011), the link between these conditions and spatial patterns of sap flow and their controls is still not well understood. Additionally, most studies which include site-specific controls focus on a seasonal basis or undertake plot comparisons. The temporal dynamics of the different predictor categories showed contrasting dependency on potential evaporation (Fig. 9). While the stand- and site-specific predictors as well as DBH and tree height remained fairly constant in their total explained variance, for both sap velocity and sap flow, the species-dependent temporal variance in the sap velocity models was strongly correlated to the dynamics of $E_{\text {pot }}$ (Table 2). The species effect in this context is the contrast between oaks, which can respond to increasing $E_{\text {pot }}$ only up to a certain threshold (Fig. 5b), and beech trees, which can reach higher sap velocities when they are not water-limited. A second predictor with considerable positive correlation with $E_{\text {pot }}$ is aspect (Table 2), despite the fact that north- and south-facing slope locations show similar values of $E_{\text {pot }}$. If the trees were physiologically adapted to water limitation on south-facing slopes, under high- $E_{\text {pot }}$ conditions the contrast between these transpiration-limited trees and those on northfacing slopes, using their full transpiration potential, could be even stronger, leading to a very temporally dynamic influence of aspect. To separate this influence from the effect that the exact tree locations might be representing shading and landscape position in general and not necessarily strong contrasts in aspect, further studies at more pronounced northand south-facing aspects and possibly also in a very dry year could help.

Lastly, the overall explained variance of our linear models for both sap velocity and sap flow also correlates with $E_{\text {pot }}$, as it does with sap velocity (Fig. 7). The models can explain considerable proportions of the spatial variability in sap velocity and sap flow when those values themselves can become large, driven by high $E_{\text {pot }}$ and thus leading to larger transpiration contrasts in the landscape, due to species or aspect, for example. At lower values of potential evaporation, the spatial variability of sap velocity is less pronounced and not primarily determined by the predictors included in our models.

For hydrological modellers this means that at low values of potential evaporation, which likely coincide with cloudy, rainy or cold days, transpiration flux is low and contains little spatial structure. On the one hand this entails smaller potential errors in the transpiration estimates, but on the other hand, it could be considered in attempts to apply dynamic model structures. During low- $E_{\mathrm{pot}}$ days, transpira- tion could be implemented in a more general and aggregated way, whereas during high- $E_{\text {pot }}$ days including the spatial patterns of tree and site (as well as stand) characteristics could markedly improve model performance and spatial representation of transpiration.

\section{Conclusions}

Sap flow measurements are a suitable tool to investigate the different influences that shape spatial patterns of tree transpiration in a landscape. However, there are some uncertainties involved, for example the widely applied calculation of sap flow from sap velocities includes the assumption that the tree species and size are mainly determining this relationship. As ecophysiological adaptations to site conditions have been shown in other contexts, an independent determination of sap flow for each tree in the study would need direct measurements of sapwood area and other relevant xylem characteristics. This would enable a better quantification of the different influences on spatial transpiration patterns, which would complement the more exploratory character of our study.

We examined both the influences on spatial patterns of transpiration in a landscape and their temporal dynamics, by means of sap velocity and sap flow. The spatial patterns were mainly controlled by tree- and site-specific characteristics. Temporal dynamics of the overall explained variance of the linear models and the relative importance of species was closely linked to the dynamics of potential evaporation, whereas the site-specific influences remained constant over time. This means that the abiotic characteristics of the landscape control transpiration pattern to a certain extent, and this control remains static in time. However, the importance of biotic characteristics, i.e. the landscape-scale patterns of tree species distribution, varies in time and becomes most important during days of high atmospheric demand. Our results suggest that spatial representation of landscape-scale transpiration in distributed hydrological models could be improved by including spatial patterns of tree-, stand- and site-specific characteristics. For spatial sap flow patterns, these influences were considerably larger than the obvious and widely used influences of the potential evaporation and water availability in the soil. Consequently, similar to resolving agricultural areas according to crops on a field scale, one could represent the spatial structure in forest transpiration resulting from species and size distributions, but also from patterns due to site characteristics such as geology or topography. This information can be used for model parameterisation or as a part of multi-response evaluation for soil-vegetation-atmosphere transfer and hydrological models.

Additionally, identifying phases of varying importance of the different influences, and their dependence on $E_{\text {pot }}$, can help modellers decide when to best include site-specific characteristics to describe spatial patterns of transpiration in models, when a classification according to species and stands 
might be more appropriate, or when it is not necessary at all to implement a spatially explicit transpiration estimate. Thus, the spatial representation of transpiration in hydrological models could be attempted in a temporally dynamic way, and, when spatial structure is needed, be based on information from geological maps, digital elevation models, forest inventories or remote sensing images.
Data availability. Data and codes used in this study are available on request from the corresponding author, Sibylle Hassler (sibylle.hassler@kit.edu). 


\section{Appendix A}

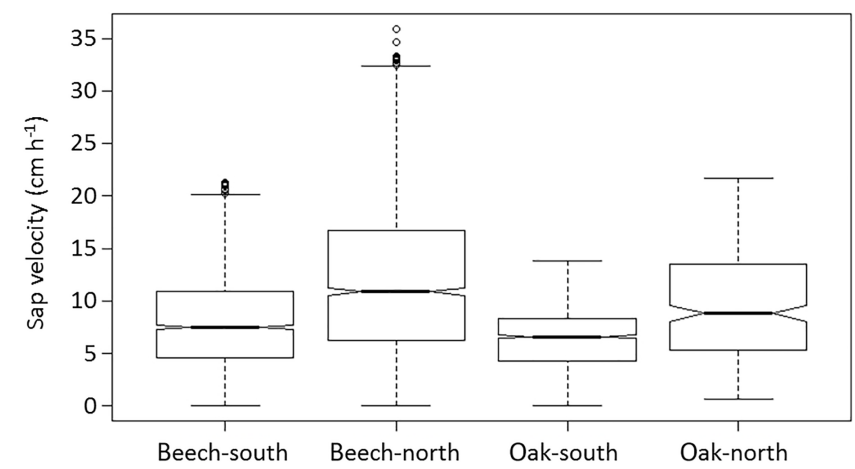

Figure A1. Sap velocities when grouped according to species and aspect.
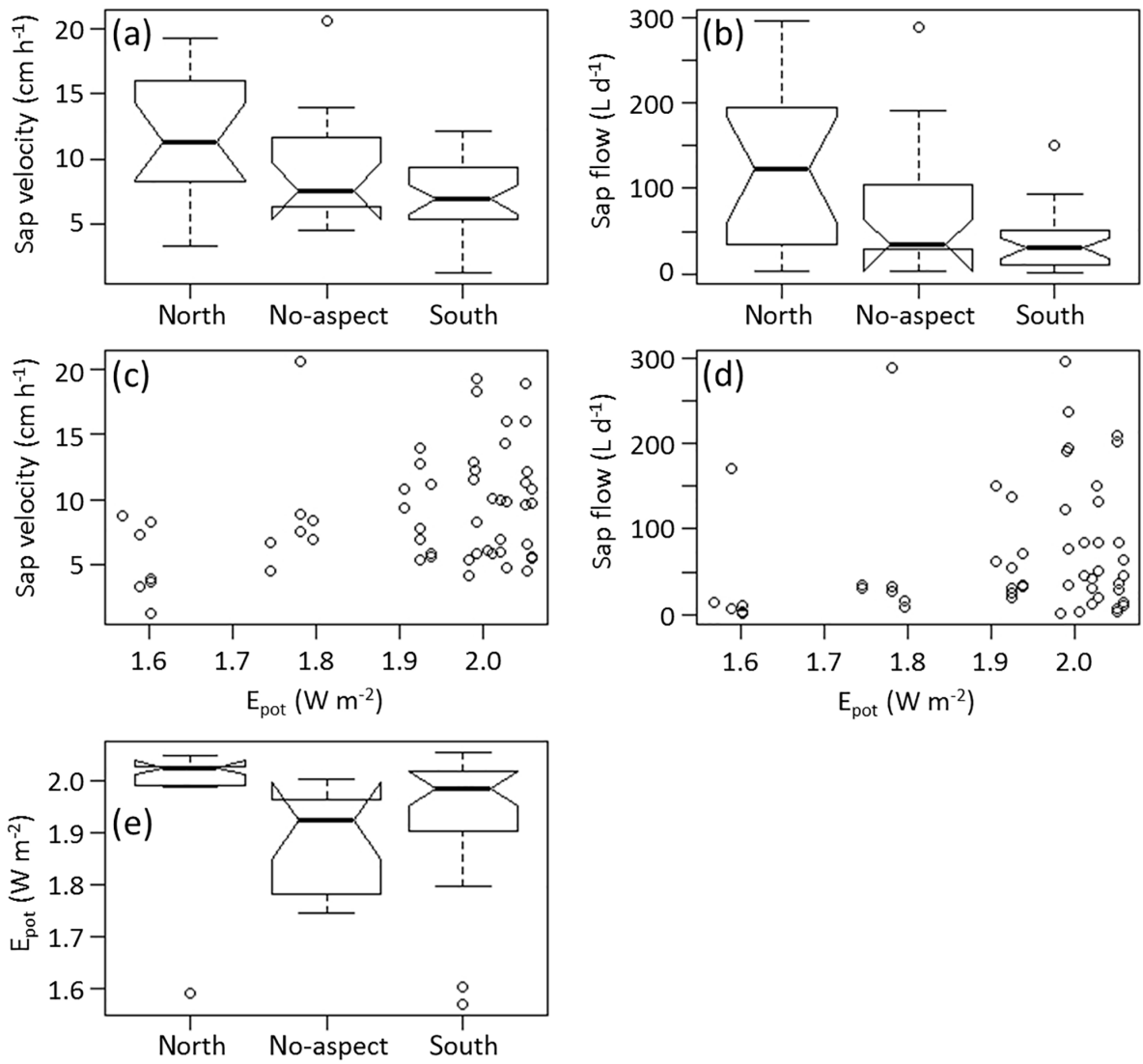

Figure A2. (a) Sap velocity and (b) sap flow values grouped according to aspect categories. (c) Sap velocities and (d) sap flow values of each tree with respect to $E_{\text {pot }}$ at the tree location. (e) $E_{\text {pot }}$ values at the tree locations values grouped according to aspect categories. Shown are temporal averages, for each tree (for sap velocity and sap flow) or each tree site (for $E_{\text {pot }}$ ). The uncharacteristically high sap flow values are probably due to overestimation during the upscaling to tree-level transpiration and should be treated with caution; however, absolute values are not of interest here, rather relations and spatial patterns which should be robust. 
Competing interests. The authors declare that they have no conflict of interest.

Acknowledgements. We thank the German Research Foundation (DFG) for funding of the CAOS research unit FOR 1598 in which this study was undertaken. We especially acknowledge Britta Kattenstroth and Jean-François Iffly for their invaluable help in setting up and running the monitoring network, as well as countless helpers during field work. Thomas Gräff and Uwe Ehret commented on an earlier version of this paper. We also acknowledge support for open-access publishing by the Deutsche Forschungsgemeinschaft (DFG) and the Open-Access Publishing Fund of Karlsruhe Institute of Technology.

The article processing charges for this open-access publication were covered by a Research

Centre of the Helmholtz Association.

Edited by: Nunzio Romano

Reviewed by: two anonymous referees

\section{References}

Adelman, J. D., Ewers, B. E., and MacKay, D. S.: Use of temporal patterns in vapor pressure deficit to explain spatial autocorrelation dynamics in tree transpiration, Tree Physiol., 28, 647-658, 2008.

Angstmann, J. L., Ewers, B. E., Barber, J., and Kwon, H.: Testing transpiration controls by quantifying spatial variability along a boreal black spruce forest drainage gradient, Ecohydrology, 6, 783-793, 2013.

Barnard, H. R., Graham, C. B., van Verseveld, W. J., Brooks, J. R., Bond, B. J., and McDonnell, J. J.: Mechanistic assessment of hillslope transpiration controls of diel subsurface flow: A steadystate irrigation approach, Ecohydrology, 3, 133-142, 2010.

Boer-Euser, T., McMillan, H. K., Hrachowitz, M., Winsemius, H. C., and Savenije, H. H. G.: Influence of soil and climate on root zone storage capacity, Water Resour. Res., 52, 2009-2024, 2016.

Bolte, A., Rahmann, T., Kuhr, M., Pogoda, P., Murach, D., and von Gadow, K.: Relationships between tree dimension and coarse root biomass in mixed stands of European beech (Fagus sylvatica L.) and Norway spruce (Picea abies [L.] Karst.), Plant Soil, 264, 1-11, 2004.

Bond, B. J., Jones, J. A., Moore, G., Phillips, N., Post, D., and McDonnell, J. J.: The zone of vegetation influence on baseflow revealed by diel patterns of streamflow and vegetation water use in a headwater basin, Hydrol. Process., 16, 1671-1677, 2002.

Bosch, D. D., Marshall, L. K., and Teskey, R.: Forest transpiration from sap flux density measurements in a Southeastern Coastal Plain riparian buffer system, Agr. Forest Meteorol., 187, 72-82, 2014.

Bovard, B. D., Curtis, P. S., Vogel, C. S., Su, H. B., and Schmid, H. P.: Environmental controls on sap flow in a northern hardwood forest, Tree Physiol., 25, 31-38, 2005.

Burgess, S. S. O., Adams, M. A., Turner, N. C., Beverly, C. R., Ong, C. K., Khan, A. A. H., and Bleby, T. M.: An improved heat pulse method to measure low and reverse rates of sap flow in woody plants, Tree Physiol., 21, 589-598, 2001.

Campbell, G. S., Calissendorff, C., and Williams, J. H.: Probe for measuring soil specific heat using a heat-pulse method, Soil Sci. Soc. Am. J., 55, 291-293, 1991.

Čermák, J. and Prax, A.: Water balance of a Southern Moravian floodplain forest under natural and modified soil water regimes and its ecological consequences, Ann. For. Sci., 58, 15-29, 2001.

Cienciala, E., Mellander, P.-E., Kučera, J., Opluštilová, M., Ottosson-Löfvenius, M., and Bishop, K.: The effect of a northfacing forest edge on tree water use in a boreal Scots pine stand, Can. J. Forest Res., 32, 693-702, 2002.

Clausnitzer, F., Köstner, B., Schwärzel, K., and Bernhofer, C.: Relationships between canopy transpiration, atmospheric conditions and soil water availability-Analyses of long-term sap-flow measurements in an old Norway spruce forest at the Ore Mountains/Germany, Agr. Forest Meteorol., 151, 1023-1034, 2011.

Dalsgaard, L., Mikkelsen, T. N., and Bastrup-Birk, A.: Sap flow for beech (Fagus sylvatica L.) in a natural and a managed forest Effect of spatial heterogeneity, J. Plant Ecol., 4, 23-35, 2011.

Dormann, C. F., Purschke, O., Carcía Marquéz, J. R., Lautenbach, S. and Schröder, B.: Components of uncertainty in species distribution analysis: A case study of the Great Grey Shrike, Ecology, 89, 3371-3386, 2008.

Elsner, G.: Morphological variability of oak stands (Quercus petraea and Quercus robur) in northern Germany, Ann. For. Sci., 50, 228s-232s, 1993.

Fahle, M. and Dietrich, O.: Estimation of evapotranspiration using diurnal groundwater level fluctuations: Comparison of different approaches with groundwater lysimeter data, Water Resour. Res., 50, 273-286, 2014.

Fenicia, F., Kavetski, D., Savenije, H. H. G., and Pfister, L.: From spatially variable streamflow to distributed hydrological models: Analysis of key modeling decisions, Water Resour. Res., 52, 954-989, 2016.

Fuchs, S., Leuschner, C., Link, R., Coners, H., and Schuldt, B.: Calibration and comparison of thermal dissipation, heat ratio and heat field deformation sap flow probes for diffuse-porous trees, Agr. Forest Meteorol., 244-245, 151-161, 2017.

Gebauer, T., Horna, V., and Leuschner, C.: Variability in radial sap flux density patterns and sapwood area among seven cooccurring temperate broad-leaved tree species, Tree Physiol., 28, 1821-1830, 2008.

Gebauer, T., Horna, V., and Leuschner, C.: Canopy transpiration of pure and mixed forest stands with variable abundance of European beech, J. Hydrol., 442-443, 2-14, 2012.

Ghimire, C. P., Lubczynski, M. W., Bruijnzeel, L. A., and ChavarroRincón, D.: Transpiration and canopy conductance of two contrasting forest types in the Lesser Himalaya of Central Nepal, Agr. Forest Meteorol., 197, 76-90, 2014.

Granier, A., Biron, P., and Lemoine, D.: Water balance, transpiration and canopy conductance in two beech stands, Agr. Forest Meteorol., 100, 291-308, 2000.

Grömping, U.: Estimators of relative importance in linear regression based on variance decomposition, Am. Stat., 61, 139-147, 2007.

Hajek, P., Kurjak, D., von Wühlisch, G., Delzon, S., and Schuldt, B.: Intraspecific variation in wood anatomical, hydraulic, and foliar traits in ten European beech prove- 
nances differing in growth yield, Front. Plant Sci., 7, 791, https://doi.org/10.3389/fpls.2016.00791, 2016.

Hernandez-Santana, V., Hernandez-Hernandez, A., Vadeboncoeur, M. A., and Asbjornsen, H.: Scaling from single-point sap velocity measurements to stand transpiration in a multispecies deciduous forest: Uncertainty sources, stand structure effect, and future scenarios, Can. J. Forest Res., 45, 1489-1497, 2015

Hölscher, D., Koch, O., Korn, S., and Leuschner, C.: Sap flux of five co-occurring tree species in a temperate broad-leaved forest during seasonal soil drought, Trees-Struct. Funct., 19, 628-637, 2005.

Holst, J., Grote, R., Offermann, C., Ferrio, J. P., Gessler, A., Mayer, H., and Rennenberg, H.: Water fluxes within beech stands in complex terrain, Int. J. Biometeorol., 54, 23-36, 2010.

Ibanez, C. A. G., Carcellar III, B. G., Paringit, E. C., Argamosa, R. J. L., Faelga, R. A. G., Posilero, M. A. V., Zaragosa, G. P., and Dimayacyac, N. A.: Estimating DBH of trees employing multiple linear regression of the best LiDAR-derived parameter combination automated in python in a natural broadleaf forest in the Philippines, Int. Arch. Photogramm., 41, 657-662, 2016.

IUSS Working Group WRB: World reference base for soil resources 2006, A framework for international classification, correlation and communication, World Soil Resources Reports, FAO, Rome, 2006.

Jackisch, C.: Linking structure and functioning of hydrological systesm - How to achieve necessary experimental and model complexity with adequate effort, Thesis, KIT Karlsruhe, https://doi.org/10.5445/IR/1000051494, 2015.

Jasechko, S., Sharp, Z. D., Gibson, J. J., Birks, S. J., Yi, Y., and Fawcett, P. J.: Terrestrial water fluxes dominated by transpiration, Nature, 496, 347-350, 2013.

Jonard, F., André, F., Ponette, Q., Vincke, C., and Jonard, M.: Sap flux density and stomatal conductance of European beech and common oak trees in pure and mixed stands during the summer drought of 2003, J. Hydrol., 409, 371-381, 2011.

Jung, E.-Y., Otieno, D., Kwon, H., Berger, S., Hauer, M., and Tenhunen, J.: Influence of elevation on canopy transpiration of temperate deciduous forests in a complex mountainous terrain of South Korea, Plant Soil, 378, 153-172, 2014.

Kleidon, A. and Renner, M.: Thermodynamic limits of hydrologic cycling within the Earth system: concepts, estimates and implications, Hydrol. Earth Syst. Sci., 17, 2873-2892, https://doi.org/10.5194/hess-17-2873-2013, 2013.

Köstner, B., Granier, A. and Cermák, J.: Sapflow measurements in forest stands: Methods and uncertainties, Ann. Sci. Forest., 55, 13-27, 1998.

Kumagai, T., Aoki, S., Shimizu, T., and Otsuki, K.: Sap flow estimates of stand transpiration at two slope positions in a Japanese cedar forest watershed, Tree Physiol., 27, 161-168, 2007.

Loranty, M. M., MacKay, D. S., Ewers, B. E., Adelman, J. D., and Kruger, E. L.: Environmental drivers of spatial variation in whole-tree transpiration in an aspen-dominated uplandto-wetland forest gradient, Water Resour. Res., 44, W02441, https://doi.org/10.1029/2007WR006272, 2008.

Loritz, R., Hassler, S. K., Jackisch, C., Allroggen, N., van Schaik, L., Wienhöfer, J., and Zehe, E.: Picturing and modeling catchments by representative hillslopes, Hydrol. Earth Syst. Sci., 21, 1225-1249, https://doi.org/10.5194/hess-21-1225-2017, 2017.
Lüttschwager, D. and Remus, R.: Radial distribution of sap flux density in trunks of a mature beech stand, Ann. Forest Sci., 64, 431-438, 2007.

Martínez-Carreras, N., Krein, A., Gallart, F., Iffly, J.-F., Hissler, C., Pfister, L., Hoffmann, L., and Owens, P. N.: The influence of sediment sources and hydrologic events on the nutrient and metal content of fine-grained sediments (attert river basin, Luxembourg), Water Air Soil Poll., 223, 5685-5705, 2012.

Meinzer, F. C., Bond, B. J., Warren, J. M., and Woodruff, D. R.: Does water transport scale universally with tree size?, Funct. Ecol., 19, 558-565, 2005.

Moore, G. W., Jones, J. A., and Bond, B. J.: How soil moisture mediates the influence of transpiration on streamflow at hourly to interannual scales in a forested catchment, Hydrol. Process., 25, 3701-3710, 2011.

Mitchell, P. J., Benyon, R. G., and Lane, P. N. J.: Responses of evapotranspiration at different topographic positions and catchment water balance following a pronounced drought in a mixed species eucalypt forest, Australia, J. Hydrol., 440-441, 62-74, 2012.

Nadezhdina, N. and Čermák, J.: Instrumental methods for studies of structure and function of root systems of large trees, J. Exp. Bot., 54, 1511-1521, 2003.

Oren, R. and Pataki, D. E.: Transpiration in response to variation in microclimate and soil moisture in southeastern deciduous forests, Oecologia, 127, 549-559, 2001.

Oren, R., Zimmermann, R., and Terbough, J.: Transpiration in Upper Amazonia Floodplain and Upland Forests in Response to Drought-Breaking Rains, Ecology, 77, 968-973, 1996.

Otieno, D., Li, Y., Ou, Y., Cheng, J., Shizhong, L., Tang, X., Zhang, Q., Jung, E.-Y., Zhang, D., and Tenhunen, J.: Stand characteristics and water use at two elevations in a sub-tropical evergreen forest in southern China, Agr. Forest Meteorol., 194, 155-166, 2014.

Pfister, L., Humbert, J., and Hoffmann, L.: Recent trends in rainfallrunoff characteristics in the Alzette River basin, Luxembourg, Climatic Change, 45, 323-337, 2000.

Pielke Sr., R. A.: Land use and climate change, Science, 310, 1625 1626, 2005.

Rabadán, M.-Á. V., Peña, J. S., and Adán, F. S.: Estimation of diameter and height of individual trees for Pinus sylvestris L. based on the individualising of crowns using airborne LiDAR and the National forest inventory data, Forest Systems, 25, e046, https://doi.org/10.5424/fs/2016251-05790, 2016.

R Development Core Team: R: A language and environment for statistical computing, R Foundation for Statistical Computing, Vienna, Austria, 2014.

Renner, M., Hassler, S. K., Blume, T., Weiler, M., Hildebrandt, A., Guderle, M., Schymanski, S. J., and Kleidon, A.: Dominant controls of transpiration along a hillslope transect inferred from ecohydrological measurements and thermodynamic limits, Hydrol. Earth Syst. Sci., 20, 2063-2083, https://doi.org/10.5194/hess-202063-2016, 2016.

Rössler, G.: Rindenabzug richtig bemessen, Forstzeitung, 4, p. 21, 2008.

Schmidt, M.: Canopy transpiration of beech forests in Northern Bavaria - Structure and function in pure and mixed stands with oak at colline and montane sites, Thesis, University of 
Bayreuth, available at: https://epub.uni-bayreuth.de/646/ (last access: 22 December 2017), 2007.

Schume, H., Jost, G., and Hager, H.: Soil water depletion and recharge patterns in mixed and pure forest stands of European beech and Norway spruce, J. Hydrol., 289, 258-274, 2004.

Scudeler, C., Pangle, L., Pasetto, D., Niu, G.-Y., Volkmann, T., Paniconi, C., Putti, M., and Troch, P.: Multiresponse modeling of variably saturated flow and isotope tracer transport for a hillslope experiment at the Landscape Evolution Observatory, Hydrol. Earth Syst. Sci., 20, 4061-4078, https://doi.org/10.5194/hess-204061-2016, 2016.

Seibert, S. P., Jackisch, C., Ehret, U., Pfister, L., and Zehe, E.: Unravelling abiotic and biotic controls on the seasonal water balance using data-driven dimensionless diagnostics, Hydrol. Earth Syst. Sci., 21, 2817-2841, https://doi.org/10.5194/hess-21-28172017, 2017.

Sprenger, M., Seeger, S., Blume, T., and Weiler, M.: Travel times in the vadose zone: variability in space and time, Water Resour. Res., 52, 5727-5754, https://doi.org/10.1002/2015WR018077, 2016.

Stojnić, S., Orlović, S., Miljković, D., Galić, Z., Kebert, M., and Wuehlisch, G.: Provenance plasticity of European beech leaf traits under differing environmental conditions at two Serbian common garden sites. Eur. J. For. Res., 134, 1109-1125, 2015.

Tannenberger, F., Flade, M., Preiska, Z., and Schröder, B.: Habitat selection of the globally threatened Aquatic Warbler at the western margin of the breeding range: Implications for management, Ibis, 152, 347-358, 2010.

Traver, E., Ewers, B. E., Mackay, D. S., and Loranty, M. M.: Tree transpiration varies spatially in response to atmospheric but not edaphic conditions, Funct. Ecol., 24, 273-282, 2010.

Tromp-van Meerveld, H. J. and McDonnell, J. J.: On the interrelations between topography, soil depth, soil moisture, transpiration rates and species distribution at the hillslope scale, Adv. Water Res., 29, 293-310, 2006.

van den Bos, R., Hoffmann, L., Juilleret, J., Matgen, P., and Pfister, L.: Regional runoff prediction through aggregation of first-order hydrological process knowledge: A case study, Hydrolog. Sci. J., 51, 1021-1038, 2006.
Vandegehuchte, M. W. and Steppe, K.: Sap-flux density measurement methods: working principles and applicability, Funct. Plant Biol., 40, 213-223, 2013.

Vauhkonen, J. and Mehtätalo, L.: Matching remotely sensed and field-measured tree size distributions, Can. J. Forest Res., 45, 353-363, 2015.

Vertessy, R. A., Benyon, R. G., O'Sullivan, S. K., and Gribben, P. R.: Relationships between stem diameter, sapwood area, leaf area and transpiration in a young mountain ash forest, Tree Physiol., 15, 559-567, 1995.

Vilhar, U., Starr, M., Urbančič, M., Smolej, I., and Simončič, P.: Gap evapotranspiration and drainage fluxes in a managed and a virgin dinaric silver fir-beech forest in Slovenia: A modelling study, Eur. J. Forest Res., 124, 165-175, 2005.

Vincke, C., Breda, N., Granier, A., and Devillez, F.: Evapotranspiration of a declining Quercus robur (L.) stand from 1999 to 2001. I. Trees and forest floor daily transpiration, Ann. Forest Sci., 62, 503-512, 2005.

Wrede, S., Fenicia, F., Martínez-Carreras, N., Juilleret, J., Hissler, C., Krein, A., Savenije, H. H. G., Uhlenbrook, S., Kavetski, D., and Pfister, L.: Towards more systematic perceptual model development: A case study using 3 Luxembourgish catchments, Hydrol. Process., 29, 2731-2750, 2015.

Zanetto, A., Roussel, G., and Kremer, A.: Geographic variation of inter-specific differentiation between Quercus robur L. and Quercus petraea (Matt.) Liebl., Forest Genetics, 1, 111-123, 1994.

Zehe, E., Ehret, U., Pfister, L., Blume, T., Schröder, B., Westhoff, M., Jackisch, C., Schymanski, S. J., Weiler, M., Schulz, K., Allroggen, N., Tronicke, J., van Schaik, L., Dietrich, P., Scherer, U., Eccard, J., Wulfmeyer, V., and Kleidon, A.: HESS Opinions: From response units to functional units: a thermodynamic reinterpretation of the HRU concept to link spatial organization and functioning of intermediate scale catchments, Hydrol. Earth Syst. Sci., 18, 4635-4655, https://doi.org/10.5194/hess-18-4635-2014, 2014. 